\title{
NSAID-induced gastric damage in rats
}

\author{
ABR Thomson MD FRCPC
}

\begin{abstract}
ARTICLE
Wallace JL, McKnight W, Reuter BK, Vergnolle N. NSAID-induced gastric damage in rats: requirement for inhibition of both cyclooxygenase 1 and 2 . Gastroenterology 2000;119:706-14.
\end{abstract}

\section{A PARADIGM SHIFT?}

Selective inhibition of cyclo-oxygenase (COX)-2 spares gastric prostaglandin synthesis, and is associated with a greatly reduced incidence of gastric erosions compared with what is observed with conventional nonsteroidal antiinflammatory drugs (NSAIDs). This led to the original hypothesis that the suppression of gastric COX-1 by NSAIDs is the key mechanism responsible for erosion formation. Curiously, in mice in which the gene for COX-1 is disrupted, there is reduced gastric prostaglandin synthesis but no gastric injury. Wallace and co-workers cleverly postulated that reduced COX-1 activity alone is not sufficient for erosion formation. A selective inhibition of COX-1, a selective COX-2 inhibitor, a combination of both inhibitors and a COX-1 preferential inhibitor were evaluated in rats in terms of their production of gastric damage, leukocyte adherence to vascular endothelin and gastric blood flow. Celecoxib, a COX-2 inhibitor, did not affect gastric prostaglandin $\mathrm{E}_{2}$ synthesis and did not cause gastric damage. The selective COX-1 inhibitor markedly reduced gastric prostaglandin synthesis and platelet COX-1 activity, but did not affect COX-2 and, importantly, did not cause gastric damage. Of major interest, however, is that the combination of the COX-1 and the COX-2 inhibitors caused hemorrhagic erosion formation. The COX-2 inhibitor increased leukocyte adherence, whereas the COX-1 inhibitor reduced gastric blood flow. The authors interpreted these results to suggest that "...inhibition of both COX-1 and COX-2 is required for the development of gastric erosion after NSAID administration in the rat". There appears to be distinctive mechanisms through which inhibition of these isoforms can contribute to the pathogenesis of NSAID-induced gastric damage. It may be incorrect to defend the concept that inhibition of COX-1 alone is the mechanism underlying NSAID-induced gastric injury.

Division of Gastroenterology, Department of Medicine, University of Alberta, Edmonton, Alberta

Correspondence: Dr Alan BR Thomson, 519 Newton Research Building, University of Alberta, Edmonton, Alberta T6G $2 \mathrm{C} 2$.

Telephone 780-407-6490,fax 780-407-7964,e-mail alan.thomson@ualberta.ca 


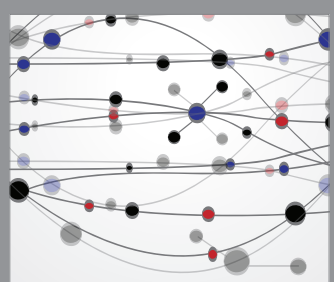

The Scientific World Journal
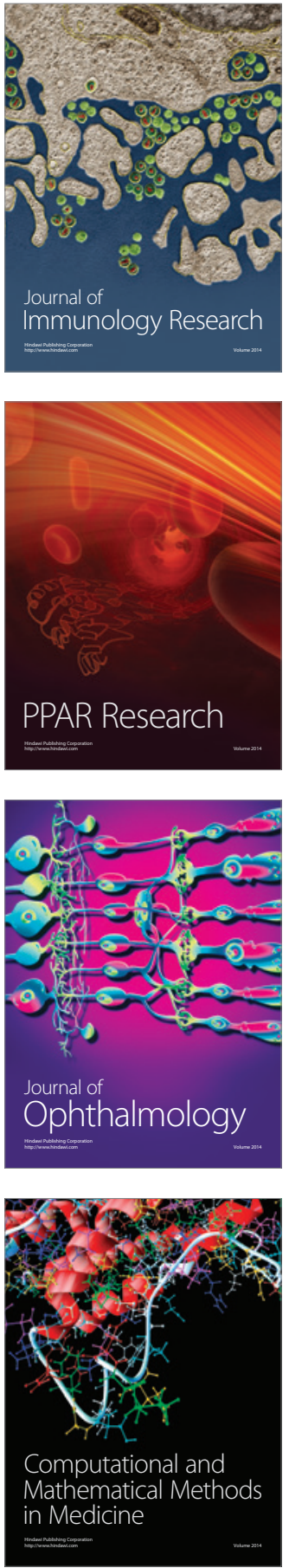

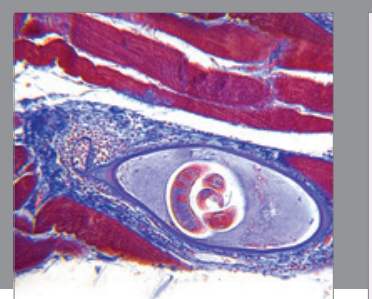

Gastroenterology Research and Practice

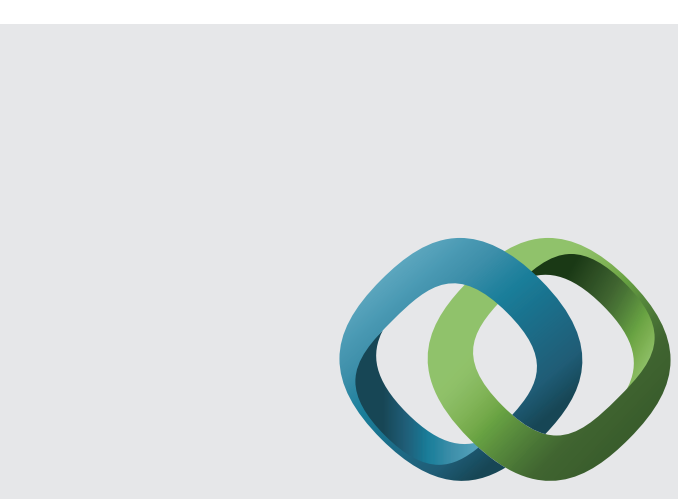

\section{Hindawi}

Submit your manuscripts at

http://www.hindawi.com
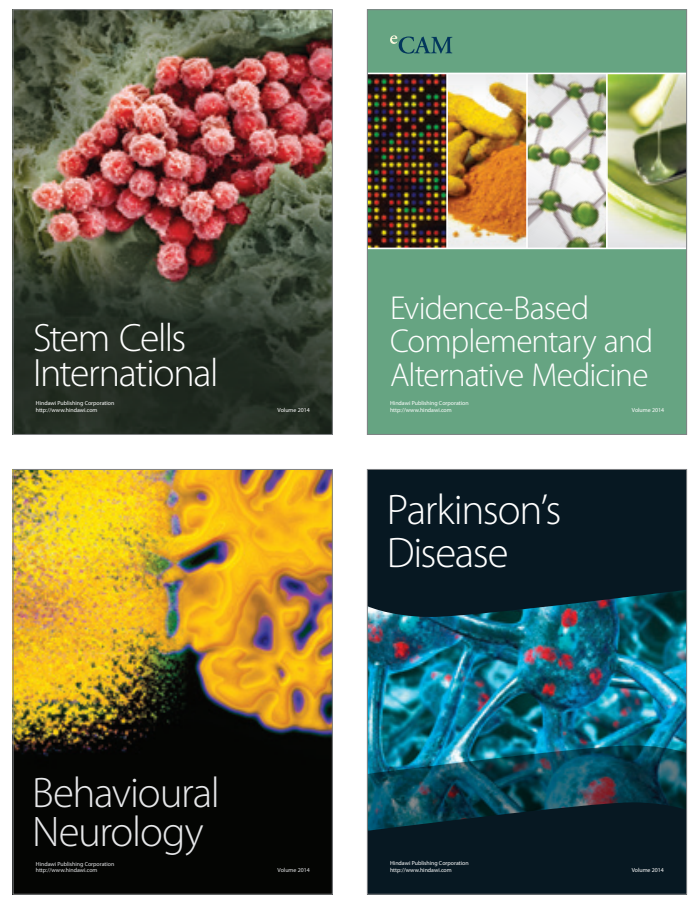
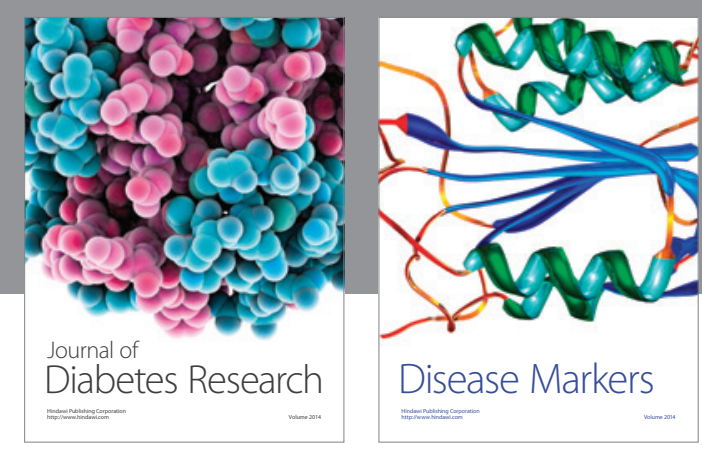

Disease Markers
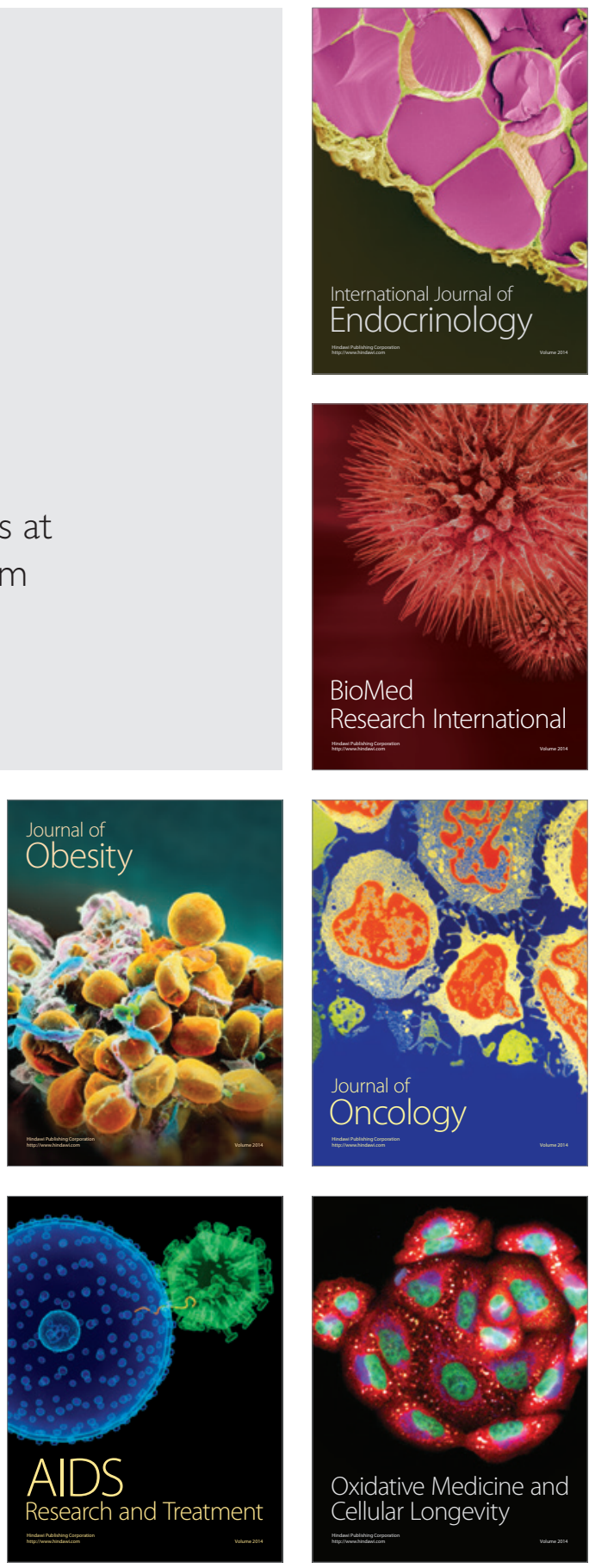